\title{
A validated measure of adherence to antibiotic prophylaxis in children with sickle cell disease
}

This article was published in the following Dove Press journal:

Patient Preference and Adherence

8 June 2016

Number of times this article has been viewed

\author{
Natalie A Duncan' \\ William G Kronenberger ${ }^{2}$ \\ Kisha C Hampton' \\ Ellen M Bloom' \\ Angeli G Rampersad' \\ Christopher P Roberson' \\ Amy D Shapiro'
}

'Department of Hematology, Indiana Hemophilia and Thrombosis Center, ${ }^{2}$ Department of Psychiatry, Indiana University School of Medicine Riley and Child Adolescent Psychiatry Clinic, Indianapolis, IN, USA
Correspondence: Natalie A Duncan Indiana Hemophilia and Thrombosis Center, 8326 Naab Rd, Indianapolis, IN 46260, USA

Tel + I $31787 \mid$ 00II ext 273

Fax + I31787I 0010

Email nduncan@ihtc.org
Background: Antibiotic prophylaxis is a mainstay in sickle cell disease management. However, adherence is estimated at only $66 \%$. This study aimed to develop and validate a Sickle Cell Antibiotic Adherence Level Evaluation (SCAALE) to promote systematic and detailed adherence evaluation.

Methods: A 28-item questionnaire was created, covering seven adherence areas. General Adherence Ratings from the parent and one health care provider and medication possession ratios were obtained as validation measures.

Results: Internal consistency was very good to excellent for the total SCAALE $(\alpha=0.89)$ and four of the seven subscales. Correlations between SCAALE scores and validation measures were strong for the total SCAALE and five of the seven subscales.

Conclusion: The SCAALE provides a detailed, quantitative, multidimensional, and global measurement of adherence and can promote clinical care and research.

Keywords: penicillin prophylaxis, SCAALE, newborn screening program, Sickle SAFE Program, hemoglobinopathy, compliance

\section{Background}

Children with sickle cell disease (SCD) have compromised splenic function that increases the rate of bacteremia with the ensuing risk of rapid progression to sepsis, septic shock, and death. ${ }^{1,2}$ Penicillin prophylaxis has become a mainstay in the management of children with SCD to prevent complications relating to infection. ${ }^{3}$ With the implementation of prophylactic antibiotic prescribing, the risk of bacteremia in febrile children with SCD has decreased from 3\%-5\%, as documented from 1975 to $2002,{ }^{4-10}$ to $<1 \%{ }^{2,11}$

Yet, in spite of penicillin's effectiveness, adherence to the twice-daily treatment regimen is of enduring concern. ${ }^{12-22}$ Low adherence rates illustrate the need for an ongoing and systematic method to measure and understand adherence in this community with the goal of improving treatment outcomes. Even a low incidence rate can affect a numerically large group of children when a disorder is as prevalent as $\mathrm{SCD},{ }^{23,24}$ and rates of bacteremia as a result of nonadherence may be higher in certain high-risk subpopulations affected by SCD. Therefore, measurement and improvement of adherence offers the potential for documenting, understanding, and improving outcomes in high-risk subpopulations and further reducing the number of bacteremia cases associated with SCD.

Several methods have been used to measure adherence in SCD. These include medical record reviews, ${ }^{20}$ urinalysis, ${ }^{13,14,17,20}$ self-/parent-report by questionnaires, interviews, or visual analog scales, ${ }^{14,18,20,25}$ parent/proxy Morisky scores,${ }^{25}$ medical provider reports, ${ }^{25}$ clinic visit attendance, ${ }^{25}$ medication event monitoring system (MEMS) pill 
bottles, ${ }^{15}$ and medication possession ratios (MPRs) using pharmacy claims ${ }^{12,16,22,26}$ or dispensation data. ${ }^{19,21,25}$ Most of these measures have been validated in other clinical populations; yet, the information we can glean from them is limited. As Beverung et al, ${ }^{12}$ who utilized an MPR, stated, "[...] we cannot explain why adherence is low $[. .$.$] ". The MPR, for$ instance, produces an adherence rating, but does not provide information on (potentially modifiable) variables underlying nonadherence. Also, MEMS and MPRs do not provide information about whether the medicine was actually given to the child or under what conditions. Furthermore, medical record reviews, urinalysis, MEMS, and MPRs are costly and time-intensive to obtain, reducing their feasibility for daily clinical use at a population level.

Furthermore, although several self- or parent-report scales have been used to measure the factors associated with antibiotic nonadherence worldwide, ${ }^{27}$ most have been used as outcome measures in assessment or treatment studies without extensive psychometric analysis to support their reliability and validity. One antibiotic adherence parent-report scale that has been extensively validated is the Parental Perception on Antibiotics scale, which was originally developed to investigate the factors related to antibiotic overuse in Saudi Arabia. ${ }^{28}$ The Parental Perception on Antibiotics scale has demonstrated good internal consistency, good face and construct validity, and good discriminant and convergent validity in parents, in particular. ${ }^{28-30}$ However, it was not developed for the unique cultural and situational aspects of care and treatment of the child with SCD.

The lack of an economically and clinically feasible instrument to measure penicillin prophylaxis adherence in SCD has resulted in almost no systematic, population-wide documentation or monitoring of adherence in daily clinical practice, despite the well-established value of penicillin prophylaxis for preventing infection in this at-risk population. This critical gap in our understanding of adherence to penicillin prophylaxis (and application of adherence knowledge to the daily clinical setting) exposes a need in SCD clinical management and research for a more feasible, clinically relevant, multidimensional measure of adherence, that is, one that has more layers of information than just a single, global score.

In light of the need for and potential benefit of a new multidimensional measure of adherence that is valid, of low cost, and provides real-time information based on the perspective of the individual most responsible for adherence (the caregiver), we developed and validated the Sickle Cell Antibiotic Adherence Level Evaluation (SCAALE)
(Supplementary material). This study aimed to describe the psychometric properties and validity of the SCAALE and demonstrate its potential utility as a clinical and research instrument. Developed using a conceptual framework of adherence first utilized in hemophilia, ${ }^{31,32}$ the SCAALE is a brief parent/guardian-report questionnaire designed to evaluate specific areas of adherence, identified as subscales, as well as global adherence to antibiotic prophylaxis.

\section{Methods}

\section{Recruitment and procedures}

The study protocol was approved by the St Vincent Hospital Institutional Review Board. Patients were recruited by Sickle SAFE (Screening, Assessment, Follow-up, and Education) Program coordinators during home visits or by telephone. All participants provided informed consent; parents/guardians consented for minor children. Participants also signed a release of information, granting permission to contact the patient's pharmacy and obtain dispensation records for the year preceding questionnaire completion. The parent/guardian was then given the SCAALE with a demographic cover sheet and allowed as much time as necessary to complete the survey.

\section{Participants}

Participants were recruited from the population of patients enrolled in the Sickle SAFE Program, the Indiana State Department of Health-supported hemoglobinopathy newborn screening (NBS) follow-up program. This program ensures timely notification of affected patients, educates families about the confirmed diagnosis and management of the disease, and links families to a hematologist. All infants in Indiana identified by the NBS laboratory as having a hemoglobinopathy are enrolled in the Sickle SAFE Program. From that population, we recruited only patients diagnosed with hemoglobin SS disease ( $\mathrm{Hb} \mathrm{SS}), \mathrm{S}$ beta thalassemia ${ }^{+}\left(\mathrm{Hb} \mathrm{S} / \beta^{+} \mathrm{Th}\right)$, $\mathrm{S}$ beta thalassemia ${ }^{0}\left(\mathrm{Hb} \mathrm{S} / \beta^{0} \mathrm{Th}\right)$, or hemoglobin SC disease (Hb SC) who had been prescribed twice-daily antibiotic prophylaxis for at least 3 months (the recall period on the questionnaire). The study was limited to English-speaking patients under 6 years of age.

\section{Measure}

The SCAALE is a 28-question survey divided into seven (four-question) subscales (Supplementary materials for SCAALE items):

- Time: Does the patient take the antibiotic on the prescribed days and at the prescribed times? 
- Dose: Does the child receive the appropriate dose of antibiotic? Do issues related to difficulty swallowing, misbehavior, or trouble measuring interfere with appropriate dosing?

- Pharmacy: Do pharmacy-related barriers, such as hours of operation and dispensation errors, limit patient adherence?

- Plan: Does the patient plan appropriately to have an adequate supply of antibiotic to be able to adhere to the regimen?

- Remember: Do issues of forgetfulness impact the patient's adherence?

- Communicate: Does the patient communicate with the child's physician at appropriate times, such as when there are questions about the antibiotic regimen or when fever $>101^{\circ} \mathrm{F}$ occurs?

- Environment: Are there environmental factors, such as financial or transportation barriers, stress, and chaos, or lack of support that contribute to nonadherence?

An eighth (five-question) subscale, Other Caretakers, with questions about other caretakers responsible for administering the antibiotic and the effect of this on adherence, was piloted based on input from the patient focus group. It remains under further review and is excluded from this report.

Questions and subscales were rationally developed and revised in a five-step process to optimize content validity: 1) initial question development by hemoglobinopathy care specialists; 2) question review by a parent/guardian focus group; 3) question revision and addition of two subscales ("Pharmacy" and "Other Caretakers") based on focus group feedback; 4) SCAALE administration to a 34-patient pilot sample for preliminary reliability and validity analysis; and 5) based on pilot sample results, slight modifications to some questions and to descriptive anchors for the scoring scale to improve sensitivity. Questions were written to reflect the caretaker's actions and experiences managing a twice-daily antibiotic schedule.

SCAALE response options are scored on five-point Likert scales ("Always", "Almost Always", "Often", "Sometimes", "Rarely or Never"). An answer of "Always" reflects the "best" possible adherence for some questions and the "worst" possible adherence for others. Questions are scored in such a way that responses indicating "worst" adherence receive one point while responses indicating "best" adherence receive five points. SCAALE subscale and total scores are the averages of the questions comprising them and range from 1 (least adherent) to 5 (most adherent). The survey asks the respondent to report adherence for the past 3 months.

\section{Validation measures of adherence}

Three adherence measures were used to demonstrate SCAALE construct validity: General Adherence Rating (GAR) by parent, GAR by health care provider, and MPR (see descriptions later). Because no single adherence measure can provide a perfect characterization of adherence ( short of a behavior coder who directly observes the child constantly), an adherence measure's validity is best captured by demonstrating significant relations between the adherence measure and several other estimates of adherence.

\section{General Adherence Rating}

The demographic cover sheet included a GAR scale on which respondents rated their global adherence level using a scale of 1 ("rarely or never" follows the doctor's instructions for antibiotic use) to 10 ("always" follows the doctor's instructions for antibiotic use). The parent completing the SCAALE and one health care provider per subject provided a GAR.

The health care provider completing the GAR was the individual who most closely follows the patient's prophylactic antibiotic treatment for SCD. Provider responses were based on a global impression of the family's adherence. Similar provider-rated global impression scales are widely used in medicine, including visual analog scales ${ }^{33}$ and global impression ratings. ${ }^{34}$

The GAR has been validated in previous adherence research. ${ }^{31,32}$

\section{Medication possession ratio}

The MPR is a widely used adherence measure and has been used in several studies evaluating antibiotic adherence in SCD. ${ }^{12,16,19,21,22}$ Advantages of the MPR are that it does not rely on self-report and the data can be obtained from known sources. However, limitations exist. Refilling a prescription is not the same as ingesting it, and MPR is best calculated in a closed pharmacy system, ${ }^{35}$ which was not available for this study.

An MPR for the 3 months preceding SCAALE completion was calculated using pharmacy dispensation records. The MPR was the ratio of the number of days during which the patient had antibiotics as indicated by the number of doses dispensed (numerator) to the number of days in the study period (90 days, denominator). An MPR of 1.0 indicates $100 \%$ adherence in terms of prescription refills relative to medication prescribed, while lower MPRs indicate that less medication was dispensed than was prescribed (lower adherence). In some cases, MPRs $>1.0$ were observed. To reflect that MPRs $>1.0$ 
did not necessarily indicate greater adherence than MPRs $=1.0$, MPR values $>1.0$ were recoded as 1.0 .

\section{Statistical analysis}

The SCAALE development process followed standardized methodology and a protocol utilizing commonly accepted statistics for validation studies..$^{36,37}$ The statistics reported are outlined later.

Descriptive statistics for SCAALE item, subscale, and total scores

Descriptive statistics and distributions (mean, range, standard deviation [SD]) of SCAALE total and all subscale scores are provided. Because most subjects report adherence to a medical regimen, it is not uncommon for scores to cluster at the upper end of the distribution. ${ }^{31,32}$ A very significant clustering of scores at the upper end of the distribution represents a ceiling effect. For SCAALE scores, ceiling effects were defined as either $90 \%$ of the answers on any question being the highest possible option (ie, 5) or $\mathrm{SD}<0.5$ and mean $>4.8$, which would indicate restricted variance.

\section{Subscale intercorrelations}

Subscale intercorrelations were calculated to investigate relations among the different areas of adherence measured by SCAALE subscales. Strong subscale intercorrelations demonstrate convergent validity, by showing the subscales measure the same construct. Intercorrelations are reported as Pearson product-moment correlation coefficients $(r)$, which range from -1.0 to +1.0 ; values closer to 0 reflect weaker relationships.

\section{Internal consistency reliability}

Internal consistency reliability (ICR) is a measure of whether a group of questions evaluate the same defined concept. This was assessed for the total SCAALE and all subscales and is reported as Cronbach's alpha $(\alpha)$. This statistic ranges from 0.0 to 1.0 ; the closer to 1.0 , the stronger the ICR. Given the short subscale length (four questions), making higher $\alpha$ more difficult to achieve, $\alpha \geq 0.8$ was considered to reflect excellent ICR; $\alpha=0.7-0.79$, very good; $\alpha=0.6-0.69$, good; and $\alpha=0.5-0.59$, minimally acceptable.

\section{Correlations with validity measures}

A valid SCAALE must accurately reflect adherence, shown by shared variance with other estimates of adherence. One test of this is a correlation between the scale score and the validity measure (either GAR or MPR). Correlations with validity measures are reported as Pearson product-moment correlation coefficients $(r)$ and associated $P$-values.

\section{Results}

\section{Demographics}

Eighty-eight families were recruited; 21 declined, primarily due to lack of interest in the study or a desire for privacy. An additional seven, who were consented by telephone, did not return mailed questionnaires. Of the 60 remaining, two participants were excluded due to age being $>6$ years. This resulted in a sample size of 58. See Table 1 for sample demographic and medical information.

\section{Question- and subscale-level descriptive data and intercorrelations}

At a question level, significant ceiling effects were found for 9/28 questions (three questions each from the "Dose", "Pharmacy", and "Environment" subscales). All score distributions were skewed negatively, that is, most data were at the high end of the distribution. Item-level data are available in Table S1.

Mean total SCAALE score was 4.7 , with a range of 3.14-5.00 (Table 2). Subscale mean scores ranged from 4.4 ("Plan") to 4.9 ("Dose" and "Environment"). The "Time", "Plan", and "Environment" subscales had the highest median intercorrelations with the other six subscales $(0.53,0.43$, and 0.40 , respectively), whereas the "Pharmacy" (0.33) and "Communicate" (0.14) subscales had the lowest median intercorrelations. The SCAALE total score was significantly correlated with all subscales ( median correlation $=0.64$, range $=0.50$ [Communicate] to 0.87 [Plan]; a table of all intercorrelations is available from the authors).

\section{Internal consistency reliability}

ICR for the total scale was excellent at $\alpha=0.89$ (Table 2). Subscale ICRs were variable, ranging from excellent 0.86 (Time), 0.83 (Communicate), and 0.82 (Plan); to very good 0.77 (Remember); to poor 0.22 (Environment), 0.24 (Pharmacy), and 0.32 (Dose). Notably, subscales with poor ICR are also those containing the most significant ceiling effects.

\section{Validity adherence measures}

Consistent with SCAALE question and subcale ratings, GAR measures were significantly negatively skewed (ie, toward the high end of the distribution). Fifty-seven (98\%) parents 
Table I Demographics

\begin{tabular}{|c|c|c|}
\hline Characteristic & $n$ & \\
\hline Mean age in years (standard deviation, median) & 58 & $2.6 I(I .7 I, 2.07)$ \\
\hline Sex, n (\%) & 58 & \\
\hline Male & & $33(56.9)$ \\
\hline Female & & $25(43.1)$ \\
\hline Diagnosis, n (\%) & 58 & \\
\hline Hemoglobin SS disease & & $33(56.9)$ \\
\hline Hemoglobin SC disease & & $19(32.8)$ \\
\hline $\mathrm{S}$ beta thalassemia plus & & $5(8.6)$ \\
\hline $\mathrm{S}$ beta thalassemia zero & & $\mathrm{I}(\mathrm{l} .7)$ \\
\hline Patient race/ethnicity, $\mathrm{n}(\%)$ & 58 & \\
\hline Black/African-American, non-Hispanic & & $50(86.2)$ \\
\hline $\begin{array}{l}\text { Black/African-American, ethnicity } \\
\text { not indicated }\end{array}$ & & $5(8.6)$ \\
\hline Other, non-Hispanic & & $2(3.4)$ \\
\hline Other, Hispanic & & $\mathrm{I}(1.7)$ \\
\hline Father's country of origin, $n(\%)$ & 58 & \\
\hline USA & & $47(81.0)$ \\
\hline New Guinea & & $2(3.4)$ \\
\hline Nigeria & & $2(3.4)$ \\
\hline Togo & & $2(3.4)$ \\
\hline $\begin{array}{l}\text { Other (one from each: Germany, Ghana, } \\
\text { Mali, Puerto Rico, Sudan) }\end{array}$ & & $5(8.6)$ \\
\hline Mother's country of origin, $n(\%)$ & 58 & \\
\hline USA & & $47(81.0)$ \\
\hline New Guinea & & $2(3.4)$ \\
\hline Nigeria & & $2(3.4)$ \\
\hline Togo & & $2(3.4)$ \\
\hline $\begin{array}{l}\text { Other (one from each: Germany, Ghana, } \\
\text { Puerto Rico, Sierra Leone, Sudan) }\end{array}$ & & $5(8.6)$ \\
\hline Patient's country of origin, $n$ (\%) & 58 & \\
\hline USA & & $56(96.6)$ \\
\hline New Guinea & & $2(3.4)$ \\
\hline Household education, $\mathrm{n}(\%)$ & 57 & \\
\hline Less than high school diploma & & $7(12.1)$ \\
\hline High school graduate & & $13(22.4)$ \\
\hline Less than 2 years of college & & $19(32.8)$ \\
\hline Associate's degree & & $4(6.9)$ \\
\hline Bachelor's degree & & $7(12.1)$ \\
\hline Some graduate school & & $3(5.2)$ \\
\hline Master's degree & & $2(3.4)$ \\
\hline Doctorate degree & & $2(3.4)$ \\
\hline Person completing the scale, $n$ (\%) & 58 & \\
\hline Mother & & $52(89.7)$ \\
\hline Father & & $3(3.4)$ \\
\hline Grandmother & & $3(3.4)$ \\
\hline
\end{tabular}

provided GARs, with $89 \%$ rating their adherence 9 or 10 (mean 9.5, SD 1.05). Health care provider GARs were given for $33(56 \%)$ participants, with $61 \%$ receiving a score of 9 or 10 (mean 8.8, SD 1.25). Health care providers included primary care providers (PCPs) ( $\mathrm{n}=22,23$ subjects), hematologists ( $\mathrm{n}=4$, six subjects), and PCP with a focus on hematology ( $\mathrm{n}=1$, four subjects). Parent GAR correlated significantly with provider GAR $(0.48, P<0.01)$.
Table 2 SCAALE scores and reliability

\begin{tabular}{lllll}
\hline $\begin{array}{l}\text { SCAALE } \\
\text { section }\end{array}$ & Mean & Range & $\begin{array}{l}\text { Standard } \\
\text { deviation }\end{array}$ & $\begin{array}{l}\text { Internal consistency } \\
\text { reliability }\end{array}$ \\
\hline Total scale & 4.7 & $3.14-5.00$ & 0.37 & 0.89 \\
Time & 4.5 & $1.00-5.00$ & 0.80 & 0.86 \\
Dose & 4.9 & $3.75-5.00$ & 0.24 & 0.32 \\
Pharmacy & 4.6 & $3.25-5.00$ & 0.44 & 0.24 \\
Plan & 4.4 & $1.25-5.00$ & 0.81 & 0.82 \\
Remember & 4.7 & $2.75-5.00$ & 0.49 & 0.77 \\
Communicate & 4.6 & $1.00-5.00$ & 0.77 & 0.83 \\
Environment & 4.9 & $4.00-5.00$ & 0.23 & 0.22 \\
\hline
\end{tabular}

Abbreviation: SCAALE, Sickle Cell Antibiotic Adherence Level Evaluation.

MPRs were calculated for the 37 (64\%) participants for whom pharmacy dispensation data were available. MPR ranged from 0.11 to 1.00 (mean 0.65 , SD 0.30 ). Only $38 \%$ of the sample had MPRs $>0.80$, while $19 \%$ of the sample had MPRs of 0.33 or less. MPR correlated significantly with provider GAR $(r=0.57, P<0.02)$, but not with parent GAR $(r=0.24, P<0.15)$.

The SCAALE total score correlated significantly with parent GAR $(r=0.69, P<0.01)$, provider GAR $(r=0.44$, $P<0.05)$, and MPR $(r=0.46, P<0.01)$. The majority of SCAALE subscales also correlated significantly with two or more of the validity measures, and the "Plan" subscale correlated significantly with all three validity measures. All SCAALE subscales with the exception of "Pharmacy" and "Communicate" correlated significantly with Parent GAR. Provider GARs were significantly correlated with the "Dose" and "Plan" subscales, and correlations between Provider GAR and the "Time" and "Communicate" subscales were high $(P<0.06)$. "Time", "Plan", and "Environment" were significantly correlated with MPR (Table 3 ).

\section{Discussion}

Daily oral administration of prophylactic penicillin has significantly reduced mortality associated with bacterial infections in children with SCD. ${ }^{2,11,38}$ This treatment is recommended by the National Heart, Lung, and Blood Institute $^{39}$ as a standard of care for children with $\mathrm{Hb} \mathrm{SS}$ and $\mathrm{Hb} \mathrm{S} / \beta^{0}$ Th under 5 years of age and in older children who have had a previous severe pneumococcal infection or have functional/surgical asplenia. It was also identified in 2011 by a Sickle Cell Disease Expert Panel as a quality of care indicator rated 9 out of a possible 10 for importance. ${ }^{40}$ However, in spite of these endorsements, the effectiveness of antibiotic prophylaxis for young children with SCD may be limited by nonadherence to the treatment recommendations of twice-daily administration. There does not currently 
Table 3 Correlations for SCAALE scores and validation measures

\begin{tabular}{llll}
\hline SCAALE section & Parent General Adherence Rating & Provider General Adherence Rating & Medication possession ratio \\
\hline Total scale & $0.687^{* *}$ & $0.441^{*}$ & $0.463^{* *}$ \\
Time & $0.723^{* *}$ & 0.331 & $0.36 I^{*}$ \\
Dose & $0.315^{*}$ & $0.389^{*}$ & 0.231 \\
Pharmacy & 0.191 & 0.188 & 0.015 \\
Plan & $0.691^{* *}$ & $0.480^{* *}$ & $0.437^{* *}$ \\
Remember & $0.47 I^{* *}$ & 0.131 & 0.140 \\
Communicate & 0.230 & 0.338 & 0.298 \\
Environment & $0.434^{* *}$ & 0.081 & $0.364^{*}$ \\
\hline
\end{tabular}

Notes: $* p<0.05 ; * * p<0.01$.

Abbreviation: SCAALE, Sickle Cell Antibiotic Adherence Level Evaluation.

exist a widely accepted, validated, clinically useful means specifically designed to measure the multiple dimensions of prophylactic antibiotic adherence in SCD. This study aimed to address this gap by developing and validating a standard measure of global and specific dimensions of prophylactic antibiotic adherence in SCD: the SCAALE.

In addition to providing a global view of adherence based on a total score, the SCAALE contains seven subscales that yield more specific and detailed descriptions of different aspects of adherence. Based on prior empirical research ${ }^{31,32}$ and focus group data, adherence is not a simple unitary construct, but rather consists of, and is driven by, multiple related factors such as timing, dosing, planning, and access to medical care. Therefore, measuring the dimensions of adherence in addition to a total score is important for understanding the underlying contributors and components of nonadherence, providing a first step toward targeted interventions for at-risk families.

The complete 28-item SCAALE total score has both the strongest ICR and the strongest validity correlations with global measures of adherence as rated by parents, providers, and MPR. This is not surprising as the SCAALE total score captures all dimensions of adherence in a single measure, whereas subscales focus on specific areas of adherence that may be more important in some families and less important in others. Also, the SCAALE total score has a broader distribution and larger variance than the subscales because it consists of more items across multiple adherence areas. Finally, longer scales generally have larger ICR values than shorter scales because Cronbach's $\alpha$ is partially dependent on the length of the scale. ${ }^{36}$

Reliability and validity of the subscales were variable, with some subscales showing strong ICR and validity ("Time", "Plan", "Remember", and "Communicate") and others showing questionable ICR but significant validity correlations ("Dose" and "Environment"). The "Pharmacy" subscale, on the other hand, had poor ICR and low validity correlations, suggesting a need for additional research. The "Pharmacy" subscale is nevertheless recommended for inclusion in the SCAALE because of its content validity based on unanimous recommendation by focus group participants and experts in SCD pediatric clinical practice.

Parents and providers rated the study sample as highly adherent, as measured by GARs and the SCAALE. Studies utilizing urinalysis as an adherence measure have found that parents tend to self-report a higher level of adherence than is reflected in urinalysis. ${ }^{14,17,20}$ Thus, it is possible that the parents' GAR was somewhat inflated. However, demographic and clinical care variables support a high level of adherence in this population. Although such high adherence ratings are desirable from a clinical perspective, they limit the power of psychometric analyses by introducing restricted range and ceiling effects into the analysis. As noted under ICR, subscales with near-ceiling effects ("Dose", "Pharmacy", "Environment") had low ICR, likely reflecting insufficient variability in the sample data as opposed to poor quality of the subscales - a larger sample and further validation analysis are needed to address this question. Subscales with greater variability ("Time", "Plan", "Remember", "Communicate") had good-to-excellent ICR.

Of the subscales, "Plan" and "Time" were most consistently and significantly related to the three validity measures. This suggests that across the entire sample, behaviors related to planning to have antibiotics available and administering them at the proper time are especially important for global adherence, and therefore should be core components of adherence measurement and intervention in this population.

Our overall findings lend themselves to several implications and recommendations. The total scale score was the most reliable, valid, and best index of global adherence, reflecting its integration of multiple dimensions of adherence. It showed very strong ICR and correlations of 0.44 or higher 
with parent GAR, provider GAR, and MPR. GAR scores provided by the parent did not correlate significantly with MPR ( $r=0.24, P=0.14)$, while SCAALE total scores based on parent-report did correlate significantly with MPR $(r=0.46$, $P=0.004)$. This finding indicates that measuring global adherence based on a sum of the specific domains evaluated by the SCAALE is superior to obtaining a single global estimate provided by the parent. Such a finding also demonstrates that the core domains of the SCAALE reflect critical adherence components related to MPRs.

Our approach to SCAALE validation emphasized its relationships with multiple other methods of estimating adherence, each of which has advantages and limitations. None of the validating measures used in this study is without limitations, nor do we claim that the SCAALE is a perfect method for determining adherence. Rather, parent-report of adherence has specific advantages and contributions to estimating adherence that cannot be obtained with other methods such as MPR or GAR. Furthermore, if adherence interventions are to target parents, it is critical to understand the components and barriers to adherence based on their report. As a result, the SCAALE has a significant and important role as a parent-report measure of adherence to penicillin prophylaxis. We took a multisource (parentreport vs provider-report), multimethod (questionnaire and prescription record) approach to obtaining other validity measures of adherence for the SCAALE, demonstrating significant relationships among adherence estimates based on different methods and sources.

Although health care provider ratings of adherence have limitations, they are correlated (albeit modestly) with methods of estimating adherence. For instance, Logan et $\mathrm{al}^{41}$ found significant relationships between provider-reported estimates of adherence and patient adherence to different domains measured using the Illness Management Survey. Zeller et $\mathrm{al}^{42}$ found a significant correlation between the physicians' predictions of adherence and MEMS measures of adherence. Because health care providers see a wide range of patients, they may be able to detect extremes in adherence at above chance levels, and their perspective on adherence is valuable since it is likely to influence their medical decision making and interactions with patients. ${ }^{43}$

Importantly, the high level of adherence in our sample may, in part, reflect the degree of resources devoted to this patient group, which is actively monitored, managed, and supported by a structured NBS follow-up program. Upon receiving an abnormal hemoglobin result from the NBS laboratory, a Sickle SAFE Program coordinator contacts parents by telephone to discuss the diagnosis and schedule a home visit. The coordinator also contacts the PCP to provide education on the importance of antibiotic prophylaxis and ensure the first prescription for antibiotic prophylaxis is written. At the first home visit, when the patient is $\sim 3-6$ weeks of age, the coordinator delivers the first 3 months' supply of penicillin, provided free of charge. During the same home visit, the coordinator provides education and training on antibiotic reconstitution and dose administration. Sickle SAFE participants receive regular communications from the coordinator and a direct line remains open for the participants to contact the Program staff, which includes the coordinator and a pediatric hematologist. Moreover, if a participant loses insurance coverage, the Sickle SAFE Program provides penicillin for the uninsured period at no cost to ensure continuity of care. Research has shown that such patient-centered interactions promote adherence and lead to improved health outcomes. ${ }^{44}$ It is quite possible that lower levels of adherence would be reported in samples of patients who do not receive this level of support.

Some methodological considerations should be taken into account when interpreting results of this study. First, although the sample size of 58 was sufficient for psychometric analysis, a larger sample would likely yield greater variability among scores and may result in stronger reliability and validity statistics. It is possible that some of the weaker reliability statistics were a result of insufficient variability.

A second consideration is the skewed distribution of SCAALE scores. We believe that this reflects the tendency of this particular sample to be adherent due to frequent patient-centered interactions with the Sickle SAFE Program coordinator. While this may be a positive reflection on that program, a less-adherent sample could produce stronger reliability and validity correlations by providing a larger range of scores and wider distribution within the range. Similarly, of those patients enrolled in the Sickle SAFE Program, it is possible that only the most adherent chose to participate, introducing selection bias.

A third methodological consideration is the quality of the pharmacy dispensation data available for calculating MPRs. In spite of multiple telephone follow-ups to patients' pharmacies, dispensation records were available for only 37 (64\%) study participants. Of the data obtained, we were unable to differentiate instances of missing data (due to pharmacy error or the failure to provide a comprehensive list of pharmacies) from when patients were actually missing dispensations (due to nonadherence). To be as thorough as possible, when data were missing, a second attempt was made to gather the data 
by going back to the patient and pharmacy to check for errors in record provision or pharmacy telephone numbers.

In order to better understand group differences between subjects who did and did not have available MPR data, we compared demographic and adherence characteristics of the 21 subjects with no MPR data with demographic and adherence characteristics of the 37 subjects who provided MPR data. The results showed no difference in age $(t(56)=1.38$, $P=0.174)$ or $\operatorname{sex}\left(\chi^{2}(1)=0.001, P=1.00\right)$ between the groups. However, children with MPRs had higher adherence as rated on the SCAALE total score $(t(56)=2.16, P=0.035)$ and parent GAR $(t(55)=3.17, P=0.002)$, compared to those for whom we were unable to obtain MPRs (Table S1). The groups did not differ on provider GAR $(t(31)=1.20, P=0.028)$. These differences may reflect the fact that subjects with greater adherence live in more organized, structured, and predictable settings, which are more consistent in their use of pharmacies and, therefore, could provide more accurate data for us to use in accessing pharmacy records. As a result, MPR data may have overrepresented subjects with good adherence, although there was sufficient variability in MPR scores to allow for significant correlations with other adherence measures. The overrepresentation of good adherence in MPR data would restrict the range of adherence and may have reduced the correlations between MPR and other adherence ratings. Therefore, MPR data in a less-adherent sample may produce higher correlations and stronger validity results; this should be investigated in future research.

A fourth consideration in the interpretation of the SCAALE is the rating method, which is based on parentreport. Parent-reports are susceptible to bias and error ranging from social desirability to denial to poor self-awareness and self-monitoring. Furthermore, significant correlations between SCAALE scores and Parent GARs may be influenced by method bias because both were completed by the same rater. For this reason, we obtained adherence validity scores from three critical perspectives: parent, provider, and pharmacy dispensation data. Importantly, SCAALE total scores correlated with all three types of validity measures, demonstrating that method bias from parent-report does not account for the validity results.

While the SCAALE demonstrates strong psychometric properties and fills a critical unmet need, additional research is needed to address some shortcomings. Additional planned scale development initiatives are a test-retest stability investigation and use of the SCAALE with a large, diverse group of treatment centers with varying NBS follow-up programs. Future research may also investigate relations between the
SCAALE and other validation measures such as urinalysis, as well as validity of the SCAALE in non-English speaking samples from other countries. Also, a study is planned to evaluate hydroxyurea adherence using a similar parent-report methodological approach and including MEMS devices for scale validation, which, in spite of their own limitations, are considered by some to be the gold standard in adherence measurement. ${ }^{45}$

\section{Conclusion}

The SCAALE provides the first detailed, quantitative, dimensional, and global measurement of adherence to antibiotic prophylaxis in SCD. Evidence from this study supports the reliability and validity of the overall 28-question scale and of most subscales. Development of this scale represents an important contribution to pediatric SCD with clear applicability to clinical management, research programs, and state-funded NBS initiatives.

\section{Acknowledgment}

The authors wish to acknowledge the Indiana State Department of Health and the Indiana Hemophilia and Thrombosis Center, Inc. for their ongoing funding and support of the Sickle SAFE Program.

\section{Disclosure}

William Kronenberger, $\mathrm{PhD}$, is a research consultant for the Indiana Hemophilia and Thrombosis Center and for Shire Pharmaceuticals. The authors report no other conflicts of interest in this work.

\section{References}

1. Shankar SM, Arbogast PG, Mitchel E, Cooper WO, Wang WC, Griffin MR. Medical care utilization and mortality in sickle cell disease: a population-based study. Am J Hematol. 2005;80:262-270.

2. Baskin MN, Goh XL, Heeney MM, Harper MB. Bacteremia risk and outpatient management of febrile patients with sickle cell disease. Pediatrics. 2013;131:1035-1041

3. Brousse V, Makani J, Rees DC. Management of sickle cell disease in the community. BMJ. 2014;348:g1765.

4. Gaston MH, Verter JI, Woods G, et al. Prophylaxis with oral penicillin in children with sickle cell anemia. A randomized trial. $N$ Engl J Med. 1986;314:1593-1599.

5. Powars DR. Natural history of sickle cell disease - the first ten years. Semin Hematol. 1975;12:267-285.

6. McIntosh S, Rooks Y, Ritchey AK, Pearson HA. Fever in young children with sickle cell disease. J Pediatr. 1980;96:199-204.

7. Rogers ZR, Morrison RA, Vedro DA, Buchanan GR. Outpatient management of febrile illness in infants and young children with sickle cell anemia. J Pediatr. 1990;117:736-739.

8. Wilimas JA, Flynn PM, Harris S, et al. A randomized study of outpatient treatment with ceftriaxone for selected febrile children with sickle cell disease. N Engl J Med. 1993;329:472-476. 
9. West TB, West DW, Ohene-Frempong K. The presentation, frequency, and outcome of bacteremia among children with sickle cell disease and fever. Pediatr Emerg Care. 1994;10:141-143.

10. West DC, Andrada E, Azari R, Rangaswami AA, Kuppermann N. Predictors of bacteremia in febrile children with sickle cell disease. J Pediatr Hematol Oncol. 2002;24:279-283.

11. Rogovik AL, Friedman JN, Persaud J, Goldman RD. Bacterial blood cultures in children with sickle cell disease. Am J Emerg Med. 2010;28: 511-514.

12. Beverung LM, Brousseau D, Hoffmann RG, Yan K, Panepinto JA. Ambulatory quality indicators to prevent infection in sickle cell disease. Am J Hematol. 2014;89:256-260.

13. Buchanan GR, Smith SJ. Pneumococcal septicemia despite pneumococcal vaccine and prescription of penicillin prophylaxis in children with sickle cell anemia. Am J Dis Child. 1986;140:428-432.

14. Cummins D, Heuschkel R, Davies SC. Penicillin prophylaxis in children with sickle cell disease in Brent. BMJ. 1991;302:989-990.

15. Berkovitch M, Papadouris D, Shaw D, Onuaha N, Dias C, Olivieri NF. Trying to improve compliance with prophylactic penicillin therapy in children with sickle cell disease. Br J Clin Pharmacol. 1998;45: 605-607.

16. Davis H. Use of computerized health claims data to monitor compliance with antibiotic prophylaxis in sickle cell disease. Pharmacoepidemiol Drug Saf. 1998;7:107-112.

17. Teach SJ, Lillis KA, Grossi M. Compliance with penicillin prophylaxis in patients with sickle cell disease. Arch Pediatr Adolesc Med. 1998; 152:274-278.

18. Elliott V, Morgan S, Day S, Mollerup LS, Wang W. Parental health beliefs and compliance with prophylactic penicillin administration in children with sickle cell disease. J Pediatr Hematol Oncol. 2001; 23:112-116.

19. Sox CM, Cooper WO, Koepsell TD, DiGiuseppe DL, Christakis DA. Provision of pneumococcal prophylaxis for publicly insured children with sickle cell disease. JAMA. 2003;290:1057-1061.

20. Bitaraes EL, de Oliveira BM, Viana MB. Compliance with antibiotic prophylaxis in children with sickle cell anemia: a prospective study. J Pediatr (Rio J). 2008;84:316-322.

21. Patel NG, Lindsey T, Strunk RC, DeBaun MR. Prevalence of daily medication adherence among children with sickle cell disease: a 1-year retrospective cohort analysis. Pediatr Blood Cancer. 2010;55:554-556.

22. Warren MD, Arbogast PG, Dudley JA, et al. Adherence to prophylactic antibiotic guidelines among Medicaid infants with sickle cell disease. Arch Pediatr Adolesc Med. 2010;164:298-299.

23. Abelson RP. A variance explanation paradox: when a little is a lot Psychol Bull. 1985;97:129-133.

24. Bushman BJ, Anderson CA. Media violence and the American public. Scientific facts versus media misinformation. Am Psychol. 2001; $56: 477-489$

25. Thornburg C, Calatroni A, Telen M, Kemper A. Adherence to hydroxyurea therapy in children with sickle cell anemia. J Pediatr. 2010;156:415-419.

26. Candrilli S, O'Brien S, Ware R, Nahata M, Seiber E, Balkrishnan R. Hydroxyurea adherence and associated outcomes among Medicaid enrollees with sickle cell disease. Am J Hematol. 2011;86:273-277.

27. Alumran A, Hou XY, Hurst C. Validity and reliability of instruments designed to measure factors influencing the overuse of antibiotics. $J$ Infect Public Health. 2012;5:221-232.
28. Alumran A, Hou XY, Hurst C. Assessing the overuse of antibiotics in children in Saudi Arabia: validation of the Parental Perception on Antibiotics Scale (PAPA scale). Health Qual Life Outcomes. 2013;11:39.

29. Alumran A, Hou XY, Sun J, Yousef AA, Hurst C. Assessing the construct validity and reliability of the Parental Perception on Antibiotics (PAPA) scales. BMC Public Health. 2014;14:73.

30. Alumran A, Hou XY, Hurst C. Assessing the overuse of antibiotics in children with URTIs in Saudi Arabia: development of the parental perception on antibiotics scale (PAPA scale). JEpidemiol Glob Health 2013;3:3-10.

31. Duncan NA, Kronenberger WG, Roberson CP, Shapiro AD. VERITASPRN: a new measure of adherence to episodic treatment regimens in haemophilia. Haemophilia. 2010;16:47-53.

32. Duncan NA, Kronenberger WG, Roberson CP, Shapiro AD. VERITASPro: a new measure of adherence to prophylactic regimens in haemophilia. Haemophilia. 2010;16:247-255.

33. Wewers ME, Lowe NK. A critical review of visual analogue scales in the measurement of clinical phenomena. Res Nurs Health. 1990;13: 227-236.

34. Guy W. Clinical Global Impressions Scale(CGI). Handbook of Psychiatric Measures. Washington, DC: American Psychiatric Association; 2000:100-102.

35. Osterberg L, Blaschke T. Adherence to medication. NEngl J Med. 2005; 353:487-497.

36. Carmines EG, Zeller RA. Reliability and Validity Assessment. Thousand Oaks, CA: SAGE Publications, Inc.; 1979.

37. DeVellis RF. Scale Development: Theory and Applications. 2nd ed. Thousand Oaks, CA: Sage Publications, Inc; 2003.

38. Steinberg MH. Pneumococcus and sickle cell disease: the beginning of the end? Clin Infect Dis. 2007;44:1434-1435.

39. National Heart Lung and Blood Institute (NHLBI). Evidence-Based Management of Sickle Cell Disease: Expert Panel Report, 2014; 2014. Available from: http://www.nhlbi.nih.gov/health-pro/guidelines/sicklecell-disease-guidelines

40. Wang CJ, Kavanagh PL, Little AA, Holliman JB, Sprinz PG. Quality-ofcare indicators for children with sickle cell disease. Pediatrics. 2011;128: 484-493.

41. Logan D, Zelikovsky N, Labay L, Spergel J. The Illness Management Survey: identifying adolescents' perceptions of barriers to adherence. J Pediatr Psychol. 2003;28:383-392.

42. Zeller A, Taegtmeyer A, Martina B, Battegay E, Tschudi P. Physicians' ability to predict patients' adherence to antihypertensive medication in primary care. Hypertens Res. 2008;31:1765-1771.

43. La Greca AM, Bearman KJ. Adherence to pediatric treatment regimens. In: Roberts M, editor. Handbook of Pediatric Psychology. New York: Guilford; 2003:119-140.

44. Robinson JH, Callister LC, Berry JA, Dearing KA. Patient-centered care and adherence: Definitions and applications to improve outcomes. J Am Acad Nurse Pract. 2008;20:600-607.

45. van den Boogaard J, Lyimo RA, Boeree MJ, Kibiki GS, Aarnoutse RE. Electronic monitoring of treatment adherence and validation of alternative adherence measures in tuberculosis patients: a pilot study. Bull World Health Organ. 2011;89:632-639. 


\section{Supplementary material}

Table SI SCAALE intercorrelations between subscales

\begin{tabular}{|c|c|c|c|c|c|c|c|c|}
\hline SCAALE section & Time & Dose & Pharmacy & Plan & Remember & Communicate & Environment & Total \\
\hline Time & 1 & $0.426 * *$ & $0.36 I^{* *}$ & $0.720 * *$ & $0.654 * *$ & 0.144 & $0.626 * *$ & $0.846 * *$ \\
\hline Dose & $0.426 * *$ & I & $0.409 * *$ & $0.384 * *$ & 0.250 & 0.093 & $0.357^{* *}$ & $0.518 * *$ \\
\hline Pharmacy & $0.36 I^{* *}$ & $0.409 * *$ & I & $0.432 * *$ & $0.262^{*}$ & 0.079 & $0.303^{*}$ & $0.55 I^{* *}$ \\
\hline Plan & $0.720 * *$ & $0.384 * *$ & $0.432^{* *}$ & I & $0.536 * *$ & $0.33 I^{*}$ & $0.435 * *$ & $0.869 * *$ \\
\hline Remember & $0.654 * *$ & 0.250 & $0.262^{*}$ & $0.536 * *$ & I & 0.127 & $0.515^{* *}$ & $0.70 \mathrm{I} * *$ \\
\hline Communicate & 0.144 & 0.093 & 0.079 & $0.33 I^{*}$ & 0.127 & I & 0.160 & $0.500 * *$ \\
\hline Environment & $0.626 * *$ & $0.357 * *$ & $0.303^{*}$ & $0.435^{* *}$ & $0.515^{* *}$ & 0.160 & 1 & $0.638 * *$ \\
\hline Total & $0.846 * *$ & $0.518^{* *}$ & $0.55 I^{* *}$ & $0.869 * *$ & $0.70 \mathrm{I} * *$ & $0.500 * *$ & $0.638 * *$ & 1 \\
\hline
\end{tabular}

Notes: *Correlation is significant at the 0.05 level (two-tailed $t$-test); **correlation is significant at the 0.01 level (two-tailed $t$-test).

Abbreviation: SCAALE, Sickle Cell Antibiotic Adherence Level Evaluation.

\section{Publish your work in this journal}

Patient Preference and Adherence is an international, peer-reviewed, open access journal that focuses on the growing importance of patient preference and adherence throughout the therapeutic continuum. Patient satisfaction, acceptability, quality of life, compliance, persistence and their role in developing new therapeutic modalities and compounds to optimize clinical outcomes for existing disease states are major areas of interest for the journal. This journal has been accepted for indexing on PubMed Central. The manuscript management system is completely online and includes a very quick and fair peer-review system, which is all easy to use. Visit http://www dovepress.com/testimonials.php to read real quotes from published authors. 